Key-words: Nematoda. Oxyuridae. Syphaciinae. Parasites. 1990, 65, Suppl. I : 27-29.

Rodents. Lagomorpha. Morphology. Systematics. Numerical taxonomy. Analyse des Données. Cladistics. Evolution. Co-evolution. Zoogeography.

Mots-clés : Nematoda. Oxyuridae. Syphaciinae. Parasites. Rongeurs. Lagomorphes. Morphologie. Systématique. Taxonomie numérique. Analyse des Données. Cladistique. Évolution. Coévolution. Zoogéographie.

\title{
THE SYPHACIINAE (OXYURIDAE, NEMATODA) PARASITIC IN RODENTS AND LAGOMORPHA. NUMERICAL TAXONOMY. CLADISTIC ANALYSIS OF EVOLUTION
}

\author{
J.-P. HUGOT
}

\section{SUMMARY}

Two different methods are successively used for the systematic study of the Syphaciinae, a parasitic group of pin-worms specific for the Rodents and Lagomorpha. The statistical method permits to build a «phenetic classification »; the cladistic method permits to build a "phylogenetic classification ".
The classification finaly proposed is principaly found on the results of the morphological study of the parasites, but has also in view the integration of all available data concerning the biology, the biogeography and the phylogeny of the hosts.

RÉSumÉ : Les Syphaciiinae (Oxyuridae, Nematoda) parasites de Rongeurs et de Lagomorphes. Taxonomie numérique. Analyse cladistique de l'évolution.

L'étude des Syphaciinae, un groupe d'Oxyuridae parasites spécifiques de Rongeurs et de Lagomorphes, permet d'utiliser successivement chacune des deux principales méthodes qui sont actuellement à la disposition des systématiciens : la méthode statistique, qui permet de construire des classifications dites "phénétiques", et la méthode cladistique, qui permet de construire des classifications dites "phylogénétiques ».
La classification finalement proposée, qui est basée principalement sur les résultats de l'étude morphologique, cherche également à intégrer les informations disponibles concernant la biologie, la biogéographie et l'histoire évolutive des hôtes.

\section{INTRODUCTION}

Two different methods were used to analyze the systematics of the Syphaciinae, a parasitic group of pinworms specific to rodents and lagomorphs. Numerical and cladistic methods were used to construct both "phenetic » and «phylogenetic » classification, respectively.

The classification finally proposed is based not only on the results of the morphological study of the parasites but also takes into consideration all available data concerning the biology, biogeography, and phylogeny of the hosts. The Oxyurida have developed biologically distinctive features. Although their cycle is monoxenous, the adaptation to hosts which acquired « caecotrophy » (reingestion of the

Laboratoire de Zooologie-Vers, associé au C. N. R. S., Muséum National d'Histoire Naturelle, 61, rue de Buffon, F 75231 Paris Cedex 05, France. caecal content), allowed the infective larvae to suppress, almost completely, their passage through the outside environment. The result is that, during evolution, host « captures » were rather less frequent than in other parasitic groups. The Syphaciinae had a peculiar success with their specific hosts : they are parasitic in nineteen families and eighty genera of the Rodentia, and one family and four genera of the Lagomorpha. Paleontological and paleogeographical data concerning these two groups of hosts therefore provide some relevant comparisons when one tries to interpret the result of the morphological analysis of the parasites. In addition, evidence can occasionally be obtained from data provided through the analysis of the parasites to support hypothesis concerning evolution of the hosts.

\section{MATERIAL AND METHODS}

One hundred and one species of pinworms parasitic in rodents and lagomorphs were studied. Morphological characters were 


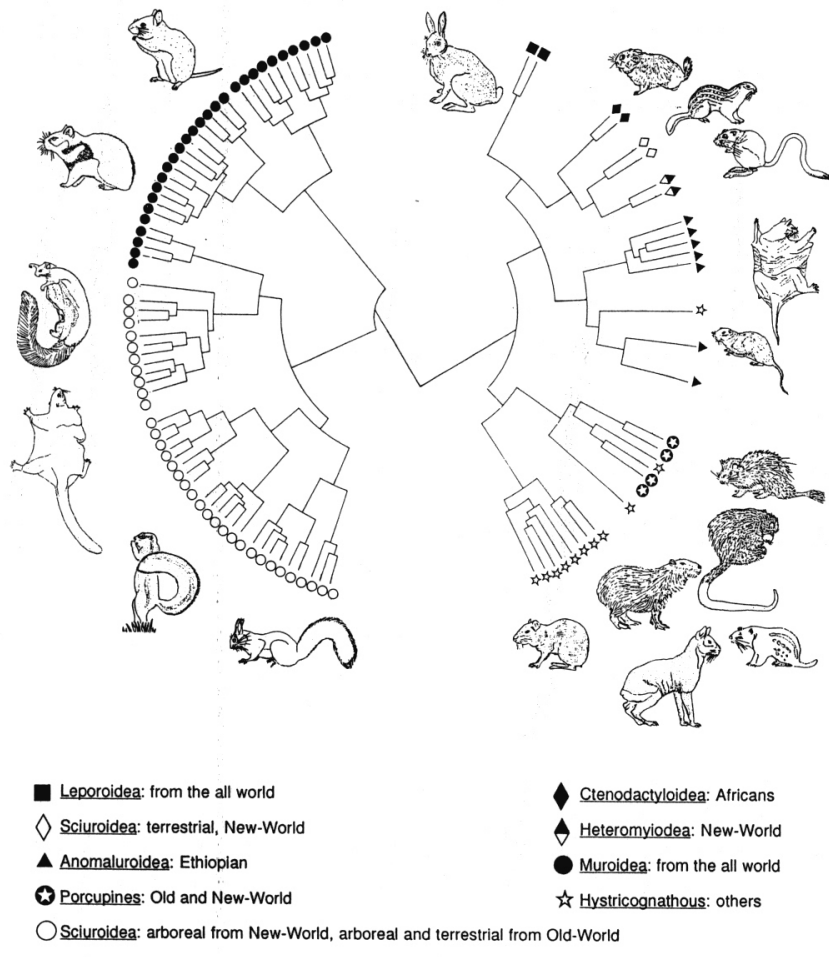

FIG. 1. - The Syphaciinae Railliet, 1916. Results of the " Hierarchical Ascendant Classification ». One hundred-and-one parasites species are described with three-hundred and twenty-two binary characters. The software used belongs to ADDAD, version 1983 du CIRCE (91405, Campus d'Orsay) : DISLOG-110 (Calcul de distances à partir de données logiques) by $\mathrm{M}$. Jambu and CAHDIS-213 (Classification ascendante hiérarchique) by M. Jambu.

divided into " character variables " and were coded (using binary coding) according to the presence (1), or absence (0), of attributes.

A « phenetic » classification was first constructed through a statistical evaluation of the similarity between the taxa for each character, using the statistical programs of the Benzecri's data analysis (ADDAD bookcase). Successive trials with the Benzecri's data analysis produced several patterns regrouping species into classes (Benzecri's ascending hierarchical classification). Each class wass associated with an assembly of variables and the associations were studied using factor analysis.

Subsequently, the validity of these goups of variables was tested by comparison with the result of a phylogenic interpretation of the evolution of the morphological characters, and by comparison with the geographical factors (paleontology, geographical distribution, systematic and ecology of the hosts). This later phase resulted in the clustering of the fifteen genera into five tribes.

A final analysis was conducted to study the possible phylogenetic connections between the five tribes. Several cladograms were built and compared with the current hypothesis concerning the early evolution of the rodents and lagomorphs.

\section{RESULTS}

\section{1 - The Syphaciinae considered as a monophyletic group}

The results of the detailed study of the morphological characteristics of the new systematic subdivisions suggest that they may fit within many small evolutionary lineages which developed homologous anatomical features from the same primitive structures. The Syphaciinae are interpreted as a monophyletic group from which evolutionary branches were successively isolated in association with particular groups of hosts.

\section{2 - Chronology and evolution of the Syphaciinae}

An attempt was made to reconstruct the main stages of the evolution of the Syphaciinae using all data concerning the paleogeography of their hosts. When the study of the morphological characters did not furnished sufficient data to justify one hypothesis in preference of another, it was admitted that very close relations have existed between the Syphaciinae and their hosts since the beginning of their respective radiations.

Paleocene. The Syphaciinae colonized the common ancestors of the Glira in Asia. Two principal branches became apparent: - one in the Lagomorpha from which the Passalurini were derived, - one which achieved a most impressive diversification within the Rodentia.

Lower Eocene. The Syphaciinae parasitic in rodents began to disperse. Three main groups can be distinguished: - a South-Thethysian group from which the Protozoophagini parasitic on Hystricognathous rodents were derived, - a Northern-Thethysian group from which the Syphaciini and the Acanthoxyurini differenciated and a few relictual forms belonging to the Hilgertiini parasitic on the Ctenodactylidae rodents, - a Northern-American group belonging to the Hilgertiini, with a few relict forms remaining in the rodents of the families Sciuridae and Heteromyidae.

Upper Eocene. The Protozoophagini evolved with the Phiomorpha and reached Africa. The Syphaciini began their differenciation with the Muroidea of Asia. The Acanthoxyurini entered Africa with the Anomaluroidea and a capture by a Phiomorpha led to a small lineage still represented by the genus Petronema.

Oligocene. During this period most of the present genera appeared which form two main groups: - the Protozoophagini present in South-America in the Caviomorpha, the Syphaciini, which evolved concurrently in the Cricetidae and in the Sciuridae in Asia, - the Acanthoxyurini which evolved in Africa with their specific hosts, the Anomaluridae.

Miocene. Connections between Africa and Eurasia were re-established and allowed two important radiations of the Syphaciini: - one with the Muroidea invading the Paleartic and Ethiopian regions and reaching Australia, - another radiating with the Sciuridae in the arboreal forms both in the Ethiopian and the Eastern regions.

Pliocene to present. Two important events occurred during this period: - quaternary glaciations and vicariant events affecting the Syphaciini parasitic in Sciuridae in the sunda islands, and the Acanthoxyurini parasitic in Ano- 
maluridae in the Ethiopian rain-forest, - the crossing of the Bering strait by the Syphaciini parasitic in Arvicolidae and Sciuridae.

\section{CONCLUSION}

Distinctive features in the evolution

of the Syphaciinae

Evolutionary patterns observed among the Syphaciinae and in others groups of Phasmidians Nematodes parasitic in Vertebrates including the following:

- the growth and diversification of a parasitic group was associated with the colonization of free ecological niches created during a period of rapid host radiation or dispersal,

- adaptation to the host did not produce evolutionary change (anagenetic evolution), or else, only by simple and short ranged speciations as isolations happens in the host's populations (allopatric speciation).

Evolutionary patterns distinctive of the Syphaciinae but not observed among other phasmidian groups include the following:

- host captures, which elsewere play a fundamental rode, only weakly affected the evolution of the Syphaciinae; in this sub-family the captures were few and occurred in the same host family; the evolutionary changes which resulted were of weak amplitude,
- the distribution of the Syphaciinae among their specific hosts appears closely related with the pattern of the phylogeny of the hosts.

\section{Methodological choices}

The two methods which were successively used in this study have their own advantages, disadvantages and limitations. The very important congruence which can be observed between the new classification proposed here and the older classification, indicates that neither refutes the other. Rather, they can be viewed as two essential and complementary approaches to the same problem. In any case, they remain the two principal tools available for the systematist, and because of their differences, it seems desirable that both be used concurrently.

Wathever the properties of the different methods of phenotypic analysis, the results appear frequently as a multiplicity of arrangements, each of which is equally probable from a logical view point, but contradicting each other. Only a knowledge of biological mechanisms can allow us to limit the range of the choices.

\section{REFERENCE}

Hugot J. P. : Les nématodes Syphaciinae parasites de Rongeurs et de Lagomorphes. Taxonomie. Zoogéographie. Évolution. Mém. Mus. Natl Hist. Nat., Paris [Sér. A, Zool.], 1988, 141, $1-153$. 